\title{
The environmental impacts of reprocessing used nuclear fuels: A UK case study
}

\begin{abstract}
Historically the UK implemented a "nominal" twice-through cycle whereby used nuclear fuels were reprocessed, but uranium and plutonium were not recycled: they were stored pending a future decision by the UK Government. However, the policy for managing higher activity wastes is clear: it envisages their disposal in a Geological Disposal Facility. Consultations for siting a repository - which were suspended in 2013 - have recently restarted, but the repository will not be available for several decades at the earliest. This article presents a comprehensive LCA study on the historical UK approach for managing used nuclear fuels and the UK Government policy for disposal of higher activity wastes. The underpinning purpose is to inform policy and decision-makers concerned with decisions on the future of the UK nuclear fuel cycle. The study relies on a combination of operational data from the Sellafield site - the industrial complex home to the UK reprocessing plants - and literature data on the GDF, and on a number of assumptions regarding the GDF design and disposal of higher activity wastes. The results reveal that a great proportion of the environmental impacts can be linked to two specific causes: indirect burdens from production of uranyl nitrate, which is used to separate plutonium from uranium, and copper, proposed in one scenario to be used as the outer layer of the disposal canister for High Level Waste. The results also demonstrate that the carbon intensity of the management of used nuclear fuels is practically negligible when compared with results from other LCA studies that cover the entire fuel cycle.
\end{abstract}

Keywords: Life Cycle Assessment; carbon intensity; spent nuclear fuel; reprocessing.

\section{Highlights:}

- A comprehensive LCA study on the UK approach to management of used nuclear fuels.

- Primary data from Sellafield site is used for most activities in the Foreground system.

- The major hot-spots are indirect burdens from production of uranyl nitrate and copper.

- The carbon intensity is negligible compared to the entire fuel cycle. 


\section{Introduction}

The UK has been a pioneer in the development of nuclear energy. It established the world's first civil nuclear programme; Calder Hall power station, which opened in 1956, was the first nuclear power station to deliver electricity in commercial quantities to the grid. The UK is also home to two gascooled nuclear reactor designs: Magnox and its successor the Advanced Gas-cooled Reactor (AGR). The last Magnox reactor in operation, Wylfa 1, was shut down in December 2015, and at present, the UK has a fleet of 15 operating nuclear reactors, 14 AGR and 1 PWR (Pressurised Water Reactor) [1]. At its peak, in 1997, nuclear energy was contributing $26 \%$ of UK domestic electricity production, but since then several reactors have reached their end-of-life, and nuclear contribution has declined to $20 \%$ in 2018 [2]. Further to this, almost $90 \%$ of this capacity (i.e. all the AGR reactors) is anticipated to be retired by 2030. The structure of the nuclear industry has been complicated by various divestments and changes in ownerships in recent years. Apart from uranium mining and milling, the country has full fuel cycle facilities and is self-sufficient in both the front-end (conversion, enrichment and fuel fabrication) and the back-end (reprocessing and waste treatment) [3].

With current available technologies two nuclear fuel cycles are possible (Figure 1). The once-through cycle (or "open cycle") envisages that nuclear fuel passes only once through power reactors; used nuclear fuels (UNFs) are classified as waste (and usually referred to as spent nuclear fuels) and sent to disposal. The other option, namely twice-through cycle (or "closed cycle"), aims at recycling the considerable amount of unused fissile material in UNFs by separating uranium $(\mathrm{U})$ and plutonium $(\mathrm{Pu})$ from fission products and reusing them for electricity generation purposes; the most common approach envisages mixing $U$ and $P u$ to produce mixed oxide fuel. Today, the majority of countries employs the once-through cycle. France is one of few examples to operate a full twice-through cycle, along with China and Japan that are currently building their reprocessing plants [4-6]. The UK adopted a "nominal" closed cycle approach: UNFs were reprocessed at Sellafield site but U and Pu were not reintroduced into the fuel cycle, rather they were stored at Sellafield site pending decision by the UK Government. The Sellafield site hosts two reprocessing plants: the Thermal Oxide Reprocessing Plant (THORP) which dealt with oxide fuels and was shut down at the end of 2018, and the Magnox reprocessing plant which deals with metal fuels and is planned to shut down in 2020 when all Magnox used fuels are reprocessed.

Figure 1 - Schematic illustration of the Once-Through and Twice-Through fuel cycles.

Radioactive solid wastes are produced throughout the whole nuclear fuel cycle, but especially from the back-end activities. They are classified according to radioactivity and heat generation level in high level waste (HLW), intermediate level waste (ILW), low level waste (LLW) and very low level waste (VLLW) [7]; notably, HLW and ILW are together known as higher activity wastes. In practice, HLW is the bulk of the fission product after vitrification; ILW is largely made of sheared claddings and plutonium contaminated materials; and V/LLW mostly comprises discarded equipment, tools, protective clothing or materials from decommissioning activities. Nowadays, management and disposal of nuclear solid waste constitutes a controversial topic. While VLLW, LLW and some ILW (typically short-lived ones) can be disposed in near-surface repository (e.g. the low level waste repository at Drigg, UK), HLW and ILW require different treatment. Many options have been investigated - including disposal in space and deep sea, incineration and direct injection into rock (e.g. see the recommendations of the Committee on Radioactive Waste Management to the UK government [8]) - and it is the intention of the UK [9], and most other countries [10], to dispose of higher activity wastes in deep repositories built several hundred meters underground in a geologically stable environment, usually known under the name of Geological Disposal Facility (GDF). However, 
not a single GDF has been built in the world yet; Finland and Sweden followed by France are expected to be the first countries to complete construction of GDFs. After the suspension of the 2013 consultation exercise in the UK, the process to decide on siting a repository has been reviewed and restarted. According to the timeline set up by the revised process, construction of the GDF is not expected to start for at least 25 years; with construction and operation of the facility projected to last for approximately 100 years [9].

In view of the current situation, the nuclear industry finds itself at a turning point where crucial decisions must be taken. Life-cycle thinking approaches can be used to support the decision-making process by assessing and comparing the sustainability of alternative nuclear fuel cycles and waste management options. Notably, Life Cycle Assessment (LCA) is one of the most used and widespread technique used for assessing the environmental performance of a product or service over its life cycle [11-13]. Besides assisting the decision-making process, results of an LCA study on the nuclear industry may be used to improve public attitudes towards the nuclear energy, provided that they are utilized in an open and transparent way.

A number of LCA studies and a number of review of LCA results have been conducted on the nuclear fuel cycle (e.g. [14-22] ). However, most focus on a single impact category, climate change, and none analyses the impacts of radionuclides released from operation of nuclear reactors and from disposal of nuclear waste. This article presents a comprehensive LCA study on used nuclear fuels reprocessing that aims at informing policy and decision-makers concerned with the future of the UK nuclear fuel cycle. The study covers multiple impact categories and employs a novel methodology for assessing the impact of radionuclides [23-26] developed from a detailed review of currently available impact assessment methodologies [27]. The article is organised as follows: Section 2 presents the goal and scope, system boundary, allocation methodology and impact categories considered; Section 3 displays results of the LCA study, which are then discussed in Section 4. Finally, Section 5 summarises the main conclusions and introduces the future work that originates from them.

\section{Methods}

\subsection{Goal and Scope}

The goal of this study is to evaluate the environmental impacts of reprocessing used nuclear fuels (UNFs) in the UK. As a case study, we focus on the most common type of UNFs generated in the UK: used fuels from advanced gas-cooled reactors (AGR), which were reprocessed in the Thermal Oxide Reprocessing Plant (THORP) before its closure in 2018. The study follows an attributional approach [28]: the focus is on the UK procedure before THORP closure and the current, but not yet implemented, policy for management of nuclear waste that envisages their disposal in the UK national GDF. As the objective is to describe the status quo in 2018, the fate of reprocessed uranium and plutonium is outside the scope of the study: the UK government has not reached a final decision, and current policy acknowledges various options for their use or disposal. Furthermore, commissioning and decommissioning are not considered for existing facilities, but they are for future facilities which are part of the current policy. A notable example is the Geological Disposal Facility (GDF): this is the preferred option for long-term disposal of nuclear waste, but its construction is expected to start not before a couple of decades and to be completed within the century $[9,29]$.

The functional unit corresponds to the reprocessing of UNFs assemblies containing 1 tonne of uranium pre-irradiation. In practice, this refers to the amount of uranium in fuel assemblies before being inserted into nuclear reactors. The uranium content post-irradiation is lower due to fission and other transmutation reactions converting uranium into fission products (FPs) and other actinides. 


\subsection{System boundary}

A pragmatic distinction is made between foreground and background system [30]. The former is defined as "the set of processes whose selection or mode of operation is affected directly by decisions based on the study" and the latter as "all other processes which interact with the foreground, usually by supplying or receiving material or energy" [30]. The foreground system includes all activities from receipt of UNFs at Sellafield site to disposal of solid nuclear waste in a GDF with the exception of interim storage prior to disposal of heat-generating HLW. The facility designed to interim-store this type of waste has negligible environmental impacts: it has no routine emissions, and its electric consumption is minimal. All activities included in the foreground system took place on-site at Sellafield, except for the GDF, which is assumed to be located elsewhere in England (see Section 2.3). The background system includes all processes that supply materials, chemicals and energy to support activities in the foreground. The methodological approach and the system boundary are shown in Figure 2. The foreground system consists of the following subsystems: Thermal Oxide Reprocessing Plant (THORP), Waste Treatment Plants (WTPs) and the Geological Disposal Facility (GDF).

Figure 2 - System boundary of used nuclear fuels management. THORP: Thermal Oxide Reprocessing Plant; WTPS: Waste Treatment Plants; GDF: Geological Disposal Facility; FHP: Fuel Handling Plant; R\&S: Receipt and Storage; HE \& CS: Head End and Chemical Separation; DOG: Dissolver Off-Gas; tbd: to-be-defined (identifies a future plant); WTC: Waste Treatment Complex. SETP: Segregated Effluent Treatment Plant. HALES: Highly Active Liquor Evaporation and Storage; WVP: Waste Vitrification Plant. EARP: Enhanced Actinide Removal; WPEP: Waste Packaging and Encapsulation Plant; WEP: Waste Encapsulation Plant.

\subsubsection{THORP}

THORP combines all the facilities necessary for reprocessing used uranium oxide fuels under one roof. Its construction was one of the world's most complex civil engineering projects; it began in 1984 and 10 years later the first fuel was sheared. In the system boundary in Figure 2 THORP is divided into 6 subsystems ${ }^{1}$.

UNF assemblies are transported by rail from nuclear power plants to Sellafield site in transport flasks. The Fuel Handling Plant (FHP) is responsible for their receipt, temporary storage and mechanical processing. Fuel assemblies are removed from the transport flasks, wet-stored to allow for partial decay of short-lived products (cooling), and then dismantled. Single pins are removed from assemblies, transferred to stainless steel containers and finally sent to THORP Receipt and Storage $(R \& S)$, where, if needed, they are further wet-stored to allow for additional radioactive decay. Overall, a minimum of five years of storage is needed to consider UNFs to have cooled enough to allow reprocessing to start. In the Head End (HE) fuel element assemblies are sheared into nominally five $\mathrm{cm}$ lengths via a vertically operated shear blade and collected into baskets. These are moved into dissolvers where nitric acid is used to dissolve uranium (U), plutonium (Pu) and fission products (FPs). Gas produced by the dissolution process, known as Dissolver Off-Gas (DOG), is treated by a dedicated system (DOG treatment) to remove radioactive and chemical contaminants prior to atmospheric discharge through the THORP stack. From dissolution, stainless steel claddings, namely "hulls", are removed from the basket and sent to the Waste Encapsulation Plant (WEP). The solution, on the other hand, is clarified and then routed to the Chemical Separation (CS) unit, where the PUREX solvent extraction process, by means of tributyl phosphate in kerosene as the solvent, is employed to separate FPs, $U$ and Pu. Firstly, $U$ and $P u$ are removed from the solution by transfer to the solvent; then plutonium is separated from uranium by chemical reduction. The solution containing FPs, termed highly active liquor, is routed to HALES (Highly Active Liquor Evaporation and Storage) for further

\footnotetext{
${ }^{1} \mathrm{FHP}$ is not technically part of THORP; it is a separate building whose functions serve both THORP and Magnox plants.
} 
processing. On the other hand, $\mathrm{Pu}$ and $\mathrm{U}$ are further processed via two dedicated lines, where they are purified and then converted into oxide forms representing the final valuable products produced by THORP.

\subsubsection{Waste Treatment Plants}

In addition to gaseous streams, which are discharged following treatment through a central stack, THORP routinely generates several liquid and solid waste streams. These are treated by a number of interconnected plants, whose functions are mostly shared with other facilities at Sellafield site. HALES, SETP (Segregated Effluent Treatment Plant) and EARP (Enhanced Actinide Removal Plant) are some of the plants that deal with liquid effluents, and the only ones considered in this study. HALES concentrates by evaporation and then stores the highly active liquor received from THORP, which is then routed to the Waste Vitrification Plant (WVP). EARP treats low and medium active effluents to reduce their activity level prior to discharge to sea to "as near zero as possible" [31]. It carries out two discrete processes treating bulks (low activity) and concentrates (medium activity) effluents; the latter is the only one considered hereafter as THORP contribution to bulks is in practice negligible. Two waste streams leave EARP: the majority of the activity is concentrated in the floc and sent to the Waste Packaging and Encapsulation Plant (WPEP), whilst the purified liquid stream is directly discharged to sea. Finally, SETP treats low active liquid effluents (acidic, alkaline and suspect active steam condensate streams), not requiring treatment in EARP or Site lon Exchange Plant (SIXEP) prior to sea discharge, by removing solids materials and adjusting $\mathrm{pH}$.

Solid containing radioactive wastes are treated by different plants. The Waste Vitrification Plant (WVP) converts the concentrated highly active liquor received from HALES into borosilicate glass yielding a stable and durable waste form suitable for disposal. The vitrified product is cast into stainless steel canisters [32], and is currently stored in the vitrified product store awaiting construction of the national GDF. This study assumes that HLW are then packaged into high-integrity disposal canister based on the Swedish KBS-3V concept [33] reported in Figure 3. This is one amongst other concepts currently being considered for implementation in the UK. Plutonium contaminated materials that arise daily from operations in THORP and include PVC gloves, filter, process residues and plant items are treated by the Waste Treatment Complex (WTC). This provides for the super-compaction of 2001 drums mixed solid wastes, with the resulting compact pucks stacked in larger 500 l stainless steel drums such that there is a cement annulus between the basket and the drum skin. Finally, the Waste Packaging and Encapsulation Plant (WPEP) and the Waste Encapsulation Plant (WEP) encapsulate arisings of effluent treatment flocs from EARP and multiple waste streams from THORP respectively, within a cement matrix (whose composition depends on the form and type of waste) within 500I stainless steel drums. Waste streams treated by WEP include solid fuel hulls (i.e. cladding), barium carbonate slurry (produced by the carbon-14 removal plant), multi-element bottle crud, centrifuge cake (produced by decanting of hulls) and maintenance scrap (from shear cave, basket handling cave crane and other miscellaneous items). Two further waste streams are included in the system boundary, though not being currently treated; these contain respectively AGR graphite and stainless steel fuel assembly components. Current procedure envisages these waste streams to be packaged without encapsulation in grout and stored at the Encapsulated Product Store. In this study, these waste streams are assumed to be treated in a future plant to-be-defined $(t b d)$, immobilised in a cement matrix and encapsulated in 500l stainless steel drums [34]. 


\subsubsection{Geological Disposal Facility}

As shown in Figure 2, the GDF subsystem consists of four units. We assumed the distance between the Sellafield site and the GDF being equal to $350 \mathrm{~km}$ and that transportation of packaged wastes occurs on rail [36].Transportation canisters, in which packaged waste are envisaged to be transported, are not considered due to lack of design data in publicly available literature.

The construction, operation and decommissioning units are based on the Nuclear Decommissioning Authority (NDA) generic GDF design for higher strength rock [37], one of the three designs under consideration to accommodate the UK baseline inventory of radioactive waste $[34,38,39]$. The construction of GDF includes excavation of repository at a depth of $650 \mathrm{~m}$ and building of above- and below-ground facilities. The operational phase consists of emplacement of waste and backfilling of its surroundings. The NDA design envisages that ILW/LLW are placed in disposal vaults and HLW in vertical deposition holes drilled along a series of disposal tunnels. Backfilling is carried out each time a disposal vault, a single deposition hole and a tunnel has reached full capacity. The Nirex Reference Vault Backfill (NRVB) is used for ILW/LLW [40], bentonite for deposition holes and a mixture of crushed rocks and bentonite at 70:30 ratio for HLW tunnels [37]. Finally, decommissioning of GDF involves progressive backfilling of remaining tunnels, facilities, shafts and drifts to seal the repository after end of its operational life; the same backfilling material as for HLW is assumed to be used [37].

\subsection{Life Cycle Inventory}

The foreground system (Section 2.2) was modelled by a combination of site-specific data from Sellafield Ltd. and literature data. The inventory is reported in full in Paulillo (2018), Appendix B [25]. Unit-specific operational flowsheets and data from Sellafield Ltd. constitute the basis upon which chemicals consumption, uranium oxide production and all streams linking units within THORP subsystem and between THORP, SETP, HALES and EARP have been estimated.No specific data was released by Sellafield Ltd. on the plutonium line; thus production of plutonium oxide has been estimated from industry average data, according to which UNFs post-irradiation contains around $1 \%$ plutonium (and $\sim 3 \% \mathrm{FPs}-96 \% \mathrm{U}$ ) [41]. With respect to environmental discharges, data for both liquid and air emissions for the year 2017 - which is made publicly available by the UK Environment Agency - was obtained from Sellafield Ltd.. Finally, data on electricity consumption has been estimated from Sellafield site annual consumption for each plant. Notably, electricity and process steam are supplied to Sellafield by a $188 \mathrm{MW}$ CHP plant (Fellside), which is located just outside the Sellafield site. This plant is part of the background system and has been modelled by average data from the Ecoinvent database [42].

Data for solid waste production were estimated from the 2016 UK Radioactive Waste Inventory [43]; this represents a coarse but comprehensive report of the total UK Inventory for radioactive waste with a breakdown on type and source, from which it was possible to estimate the production of specific types of waste per amount of fuel reprocessed. Data on solid waste conditioning and encapsulation, disposal canister and the specific activity of each waste type were obtained from the 2007 Derived Inventories [38,39]. Notably, the specific radioactivity of wastes does not correspond to the time at which wastes are produced, rather to that at which they are disposed. Immediate disposal is assumed for both ILW and LLW, whilst storage time of 50 years prior to disposal is assumed for HLW.

Due to lack of an operational GDF in the world, data for construction, operation and decommissioning were retrieved from the NDA's generic GDF design [37] and supplemented with the Ecoinvent database for nuclear energy [44], e.g. for use of building machine and diesel consumption in the construction phase.

Finally, according to the approach generally adopted in attributional studies, the background system is modelled with average market data [45], obtained from Ecoinvent database [42]. However, because 
several chemicals used in THORP, including barium nitrate, gadolinium nitrate and uranyl nitrate, are not covered in the database, they have been accounted only for the burdens of the reagents required for their production, according to stoichiometric ratios. An example is uranyl nitrate, which is produced from yellowcake (i.e. uranium ore) and nitric acid $(50 \% \mathrm{~mol})$ in a $3.3: 1$ molar ratio.

\subsubsection{Allocation}

Sellafield is one of the most complex industrial sites in Europe, with numerous plants and many activities taking place. UNFs reprocessing, at THORP and Magnox plants, is the most crucial but not the only activity. This implies that Waste Treatment Plants (WTPs) do not function exclusively to support a specific plant like THORP, rather they support multiple activities by treating a specific type of effluent or waste. WTPs are thus multi-input processes and the environmental burdens need to be allocated between the different inputs. Allocation is one of the most discussed methodological issues in LCA [46-48]; the International Organisation for Standardisation (ISO) recommends that whenever possible allocation should be avoided by using system expansion or subdivision [11,12]. However, given the peculiarity of the processes investigated and the consequent lack of data for applying system expansion, the allocation approach based on physical partitioning of the environmental burdens was used. Three criteria were employed according to data availability and type of information (e.g. material consumption, emission, etc.). Radioactivity was the preferred criterium to allocate radioactive emissions (either liquid or gaseous) to a specific unit, when radioactive compositions of all feed streams to a multi-input activity are known. For instance, this approach was used for allocating sea water discharges from SETP to THORP. When the radioactive compositions of all waste streams are not known or for estimating consumption of reagents and electricity, an allocation based on mass flow of feed streams was applied. For instance, this was used for allocating electricity consumption and atmospheric discharges from WEP, which treats several solid waste streams. Finally, when very little data was available on the feed streams, the number of streams feeding to the multi-input process was employed, e.g. for estimating chemical consumption of EARP.

\subsection{Environmental impact categories}

In the impact assessment phase, the emissions and inputs quantified in the inventory phase are translated into a smaller number of impacts. In this study the ILCD mid-point approach based on the ILCD (International Life Cycle Data System) recommendations was used [49,50]. All impact categories with the exception of land use and ionising radiations were included. The former was excluded due to lack of data, whilst the latter was replaced by two impact categories developed by Paulillo and colleagues [23-26] for direct discharges (named ionising radiations) and for emissions from solid waste disposed in a GDF (named ionising radiations, waste). Table 1 reports the impact categories considered in this study, along with their metrics and acronyms used in results charts.

Table 1 - Impact categories analysed

\subsection{Normalisation}

Normalisation is an optional step of LCIA that converts absolute impact scores into relative contributions to a reference situation, which usually represents the pressure on the environment at a specific scale (e.g. national, continental or global). The purpose of this step is to enable comparison amongst impact categories. Normalisation factors developed by the Joint Research Centre (JRC) were used for the ILCD impact categories [51,52]. For the ionising radiations (IR) category, a normalisation factor was calculated based on the ILCD 2010 inventory [52]; this is reported in Table 2. (Figure S1 in the Supporting Information reports the contributions by radionuclide to EU domestic impact). A 
normalisation factor for the ionising radiations, waste (IRw) category could not be developed because at present no GDF is operational.

Table 2 - Normalisation factors for the lonising Radiation (IR) category

\section{Results}

The environmental impacts of the waste management system described in Section 2.2 were calculated with $\mathrm{GaBi}$ sustainability software version 8 [53]. The following sections present results from normalisation and hot-spot analysis. The numerical environmental impact scores are reported in Table S1 in the Supporting Information.

\subsection{Normalised impacts}

Figure 4 shows normalised impacts expressed in terms of persons equivalent (pe). IR features the highest normalised impact at 1.4E4 pe, around one order of magnitude higher than toxicity (i.e. ECf, $\mathrm{HT}-\mathrm{c}$ and HT-nc) and resource depletion (RDm) categories that follow in second place. Freshwater (Ef) has the highest value (2.5E2 pe) amongst eutrophication categories (approximately equal to 2.5E2 pe), followed by marine and terrestrial. Acidification $(A)$, climate change $(C C)$, photochemical ozone formation (POF) and resource depletion water (RDw) feature comparable values, at around 3-6E1 pe, with particulate matter/respiratory inorganics (PM/RI) slightly higher, at $1.1 \mathrm{E} 2$ pe. The lowest normalised impact is shown by ozone depletion (OD) at 1.9 pe.

Figure 4 - Normalised impacts for the product system reported in Figure 2.

\subsection{Hot-spot analysis}

The main results of the hot-spot analysis are reported from Figure 5 to Figure 10; additional figures are included in Section S3 of the Supporting Information. Figure 5 shows contributions of each main subsystem - that is THORP, WTP and GDF (see Figure 2) - to the overall impact for each category, including both foreground and background activities. The chart shows that THORP has the largest share of impacts in the categories CC, Em, Et, IR, OD, POF and RDm. Specifically, THORP is responsible for $\sim 90 \%$ of impacts from ionising radiations (IR) and for over half of impacts from Em, OD and RDm.

Figure 5 - Hot-spot analysis of the three main subsystems. GDF: Geological Disposal Facility; WTPs: Waste Treatment Plants; THORP: Thermal Oxide Reprocessing Plant.

Figure 6 shows a detailed hot-spot analysis, including both impacts from direct and indirect burdens due to production of fuel, electricity and chemicals, of THORP subsystems excluding the FHP plant whose impacts are negligible; these include Receipt and Storage (R\&S), Head End (HE), and Chemical Separation (CS) and uranium and plutonium production lines (see Figure 2). Indirect burdens associated with the consumption of uranyl nitrate emerge as the major cause of environmental impacts, being responsible for over $70 \%$ of HT-c, HT-nc, ECf, Em, PM/RI and RDm impacts, and for more than half of all other impacts except $A$ and RDw at $\sim 30 \%$, and CC and OD at $\sim 20 \%$. For the categories climate change (CC) and ozone depletion (OD), indirect burdens from electricity consumption represent the main source of impacts, at over $50 \%$. Direct radioactive emissions represent the major contributor to the IR category, followed by indirect emissions from uranyl nitrate consumption. Figure 7 reports a detailed breakdown of the main radionuclides contributing to radiological impacts from atmospheric emissions. lodine-129 (I129) features the largest contribution ( 78\%), followed by krypton-85 ( $\mathrm{Kr} 85)$ at $\sim 22 \%$; remaining radionuclides impact is nugatory $(\sim 0.1 \%)$. 
Figure 6 - Detailed hot-spot analysis for THORP subsystem, including indirect and direct burdens.

Figure 7 - Radionuclides breakdown for lonising Radiation impacts from THORP atmospheric discharges.

As shown in Figure 5, the WTPs subsystem is the largest contributor to A (50\%), ECf (68\%), Ef (73\%), HT-c (53\%) and HT-nc (63\%) impact categories, has minor ( $10 \%)$ contributions to IR, and none to IRw; and is responsible for approximately $20-30 \%$ the remaining categories' scores. The hot-spot analysis for WTPs reported in Figure 8 shows that the majority of these impacts are caused by two specific plants. The Waste Vitrification Plant (WVP) contributes to more than $95 \%$ of ECf, Ef, HT-c and -nc, and RDm scores, to approximately $90 \%$ of PM/RI and $\mathrm{A}$, and to more than $70 \%$ of Em, Et and POF. SETP is the largest contributor to IR (76\%) and OD (54\%) categories. SETP and WTP are together responsible for more than $90 \%$ of water consumption (RDw). Furthermore, as shown in Figures S2 and S3 in the Supporting Information, $80-90 \%$ of WVP impacts are due to indirect burdens due to consumption of copper and cast iron, both of which are proposed to be used in the disposal canisters; whilst over $95 \%$ of SETP non-radiological impacts to indirect burdens from sodium hydroxide consumption, and radiological impacts of direct discharges to sea water.

Figure 8 - Detailed hot-spot analysis of the Waste Treatment Plants subsystem. WTC: Waste Treatment Complex. SETP: Segregated Effluent Treatment Plant. HALES: Highly Active Liquor Evaporation and Storage; WVP: Waste Vitrification Plant. EARP: Enhanced Actinide Removal; WPEP: Waste Packaging and Encapsulation Plant; WEP: Waste Encapsulation Plant.

Figure 5 shows that the GDF represents a minor contributor ( $12 \%)$ to RDm and the largest (51\%) to RDw category; in the remaining categories it features contributions ranging from $15 \%$ to $40 \%$. The GDF is also the sole source of radiological impacts from solid waste disposal (IRw). A detailed hot-spot analysis of the IRw category is reported in Figure 9 with a breakdown by waste stream (part A) and radionuclide (part B). The analysis shows that four solid waste streams contribute to over $97 \%$ of the overall impact: vitrified highly active liquor ( 32\%), multi-element bottle crud ( 35\%), AGR cladding ( 11\%) and centrifuge cake ( $17 \%)$; the remaining wastes streams combined contribute to around $3 \%$. lodine-129 (I129) and chlorine-36 (Cl36) are the two main sources of impacts at approximately $65 \%$ and $29 \%$ respectively, with uranium-234 (U234) standing as low as $3.7 \%$ and all other radionuclides combined at $2.6 \%$.

Hot-spot analysis for the remaining categories is included in the Supporting Information (Figure S4); it shows that the greatest portion of the GDF environmental impacts are due to management of the vitrified highly active liquor. A detailed hot-spot analysis for the vitrified highly active liquor stream is reported in Figure 10; this shows that the impacts originates in the construction phase, mainly due to electricity consumption and building of facilities, and in the decommission phase, due to consumption of bentonite as backfill during closure of the GDF. 
Figure 10 - Detailed hot-spot analysis for construction, transportation, operation and decommissioning of GDF for Vitrified HAL. C : Construction; O: Operation; T: Transportation; D: Decommissioning.

\section{Discussion}

\subsection{Normalised impacts: ionising radiations}

The ionising radiations (IR) category has the highest impact after normalisation by over an order of magnitude. This is surprising given the stringent limitations on radioactive discharges that are in place in the UK and in Europe, which are typically regulated under the principles of "As Low As Reasonably Practicable" and "Best Practicable Means". The former forms the cornerstone of nuclear plant operational emissions and the latter represent the means to achieve it. The high normalised impact of IR compared to other impact categories may propel the argument that radioactive emissions should be the primary target of mitigation strategies, thus leading to a disjoint approach where radiological and non-radiological impacts are treated separately. This result needs to be analysed and put into context carefully.

As discussed by Heijungs and colleagues, the procedure of normalization may introduce biases "in any direction and with any magnitude", especially in not well established and widely recognized categories dealing with a large number of substances [54]; IR is a notable example. According to the authors, the primary cause of biases is incompleteness in either or both inventories for the product system (in this study, the management of UNF) and the reference system, which in this case is the EU. Figure S1 in the Supporting Information shows the relative contribution by radionuclide to the total impact of the EU, calculated according to the ILCD 2010 inventory [51,52]. The six radionuclides contributing to over 99\% of the EU impact are also released by the activities in the foreground system; and vice versa the radionuclides having the largest contribution to the IR category in the management of used nuclear fuels (UNFs) are included in the ILCD 2010 inventory. Therefore, the product system and the reference system are consistent in terms of radionuclides covered.

Another cause to biases in the normalisation procedure is inconsistency in the geographical coverage of the product and reference system. The ILCD inventory is an updated version of the "Life Cycle Indicators for Resources" dataset, but it takes into account only domestic emissions and resources consumption in spite of the "apparent consumption" adopted in the latter, which also considers environmental impacts associated with traded goods [51,52]. Around a fifth of the IR impact is due to indirect burdens for production of uranyl nitrate, most of which can be attributed to the mining of uranium. As reported by the World Nuclear Association (WNA), most of uranium mines and all the largest ones are located outside of the European Union [55]. Their impact is not covered by the ILCD normalisation factors, thus representing a probable source of overestimation of the IR normalised score.

Besides biases in the normalisation procedure, normalised impacts need also to be contextualised. Radioactive emissions are primarily associated with the nuclear industry, whilst emissions for other classes of pollutants can usually be attributed to several industrial sectors. The nuclear industry is present in only a small number of countries in the EU, and even fewer countries carry out reprocessing operations on a commercial scale. It is thus evident why the normalised score of the ionising radiations category is large compared to other environmental categories: the magnitude of radioactive discharges is small, but the contribution of these to the total radioactive discharges in Europe is high. For example, I129, which dominates IR impacts from THORP, is a long-lived radionuclide that is primarily discharged during reprocessing operations [56]; in the EU, only France and UK carry out reprocessing on a commercial scale. 


\subsection{Hot-spot analysis}

\subsubsection{Radiological impacts}

The hot-spot analysis shows that impacts from ionising radiations are attributable to direct atmospheric emissions from THORP and indirect emissions associated with production of uranyl nitrate $^{2}$. Uranyl nitrate is used in the Chemical Separation (CS) phase in THORP to separate $\mathrm{U}$ from Pu by reduction of the latter to the unextractable $\mathrm{Pu}$ (III) [7]. It is obtained from uranium and nitric acid, but its impacts, both radiological and non-radiological, are primarily due to mining of uranium. More specifically, radiological and toxic impacts are largely caused by management of uranium tailings, whilst remaining impacts by electricity and heat production. Uranium tailings are by-products of the mining process after uranium is removed from the uranium-bearings mineral, and are a source of short- and long-term radioactive emissions, including radium-226 (whose decay product, radon-222, is the main health hazard in uranium mines), various uranium isotopes (U234, U235 and U238) and thorium-230; and also of metals - e.g. chromium, arsenic, vanadium, zinc and copper - leaching into soil and groundwater.

The results from the hot-spot analysis suggest that averting mining of additional uranium for the production of uranyl nitrate by using reprocessed uranium, or replacing uranyl nitrate altogether with an equivalent product capable of separating $U$ from $P u$ can effectively and substantially reduce the radiological impacts from direct discharges (and also part of the non-radiological impacts, see next Section). Over $95 \%$ of ionising radiations impacts from nuclear waste are caused by four waste streams (Figure 9); these are, vitrified highly active liquor disposed as High Level Waste (HLW) and multielement bottle crud, centrifuge cake and AGR cladding disposed as Intermediate Level Waste (ILW). 1129 contributes to around two thirds of the total impact, and $\mathrm{Cl} 36$ to about one third. The study performed by Radioactive Waste Management Ltd [57] on the radiological impact of nuclear wastes disposed in a Geological Disposal Facility (GDF) reports similar results: the radiological impact from ILW is larger than that from HLW, and I129 and Cl36 represent the primary sources of impact [57]. The two radiological categories discussed above deal with impacts occurring on very different time scales. Whilst radionuclides emitted through liquid and air discharges are readily available in the environment, the ones contained in nuclear waste are not. According to Radioactive Waste Management simulations [57], risk from ionising radiations arising from GDF is negligible before 2,000 years, steeply increases up to 10,000 years, and then continue raising at lower pace until 1,000,000 years. Therefore, comparison across these categories must be avoided, at least until a widely accepted framework for handling long-term emissions in LCA is conceived. A review on different approaches focused on long-term emissions from landfills [58] has set the ground for future developments.

\subsubsection{Non-radiological impacts}

The non-radiological impact categories with the highest normalised scores - i.e. the toxicity categories (ECf, HT-c, HT-nc), depletion of renewable and non-renewable resources (RDm), freshwater eutrophication (Ef), Particulate Matter/Respiratory Inorganics (PM/RI) and Acidification (A) - are linked with indirect burdens associated with production of uranyl nitrate (discussed in Section 4.2.1) and copper. Copper is central to the SKB disposal concept, which is assumed in this study for HLW disposal (see Section 2.2.2): it forms the external layer of the disposal canisters for HLW because it highly resistant to corrosion processes, enabling disposal canisters to remain intact over a 100,000year time span $[33,59]$.

\footnotetext{
${ }^{2}$ It must be noted that the approach used to modelling production of uranyl nitrate only considers the burdens associated with production of uranium and nitric acid (Section 2.3); this entails that the contributions of uranyl nitrate would be larger (albeit probably by a small amount) if operational data were available.
} 
Other categories with lower normalised impacts are still linked with production of uranyl nitrate and copper, but these are not the prevalent sources. Impacts from climate change and ozone depletion are primarily due to indirect burdens from electricity consumption, for instance in THORP. Whilst Photochemical Ozone Formation (POF) and Depletion of water (RDw) impacts are primarily linked to the Geological Disposal Facility (GDF), in particular to disposal of HLW (see Figure S4 in the Supporting Information).

The hot-spot analysis on non-radiological impacts suggests that efforts to improve the environmental performance of UNFs reprocessing should focus on copper and uranyl nitrate (see previous Section). For the former, possible strategies include reducing the thickness of the copper layer in the disposal canister (to reduce the total amount of copper used) without compromising its long-term integrity (e.g. [60]), or considering different designs that, while providing an equal level of safety, do not entail copper (e.g. [61]).

\subsubsection{The Geological Disposal Facility}

Currently, deep geological disposal represents the safest, but also the only feasible approach for long term disposal of nuclear waste, supported by the majority of nuclear countries. In 2016 the South Australia's Royal Commission on the Nuclear Fuel Cycle recommended the government to pursue establishment of disposal facilities for national and international nuclear waste [62]. The recommendations represent a fundamental change: the establishment of a central repository, possibly in remote and isolated lands, may foster its social acceptance as well as bring down capital costs. Those countries that do not support the GDF approach have yet to identify an alternative solution to the nuclear waste problem and intend to implement interim superficial wet or dry storage as a temporary solution.

Although the impacts of the GDF are minor (see previous Section), they merit discussion because they enable to draw some important conclusions. First, the fact that the construction and decommissioning phase (Figure 10), and vitrified HAL stream (Figure S3 in the Supporting Information) are the dominant factors in the environmental performance of the GDF. The design of the GDF envisages that HLW canisters are disposed in single deposition holes $5 \mathrm{~m}$ apart aligned in tunnels, whilst I-LLW are stacked in deposition vaults. This means that the amount of HLW is a key factor in determining the footprint of the GDF, and the higher the footprint the more the construction and decommissioning phases will impact [37] .

Second, both operation and transport phases have negligible impacts. The operation phase only includes filling of individual holes and tunnels for HLW and vaults for ILW with bentonite and crushed rocks; electricity consumption has not been taken into account due to lack of data, but it is unlikely to have major contributions. Because of the negligible impacts of transportation, the location of the location of the GDF is not a game-changing factor; however, it could constitute ground for discussions regarding the safety and hazard of transporting high radioactive material through the country.

Third, the GDF is based on the design for high-strength rock, one of the three designs developed for consideration in the UK [37]. However, the UK and the other countries may choose to implement different designs depending of the nature and quality of the host rock available. Thus, extending results of this study to other countries must be done with caution. For instance, it is known that evaporite rocks ${ }^{3}$ have generally very low water flow rate or perhaps even absence of groundwater flow [63], which is the major pathway for radionuclides escape. Therefore, repositories built in such

\footnotetext{
${ }^{3}$ The U.S. Waste Isolation Pilot Plant (WIPP) is the only such operational repository, excavated in a Permian layer in New Mexico
} 
environment are likely to have lower radiological impacts. An LCA study of alternative GDF designs and their potential impacts is critical, in particular to support nuclear waste management policies.

\subsection{Contextualising the impact of used nuclear fuels management}

It is important to compare the environmental impacts of nuclear waste management with those of front-end activities (e.g. mining and enrichment) to evaluate contributions to the overall impact of the nuclear fuel cycle. However, few LCA studies consider impact categories other than global warming [17]. This is probably due to the lack of knowledge regarding other kinds of emissions, but it is certainly linked to the fact that the primary objective of numerous studies is to compare energy sources only with respect to their potential to tackle global warming and climate change by curbing greenhouse gas emissions. For the climate change category, the majority of studies reports emissions lower than $30 \mathrm{~g} \mathrm{CO}_{2}$ eq. per kWh for the entire nuclear fuel cycle - although there are publications indicating higher emissions of up to $100 \mathrm{~g} \mathrm{CO}_{2} / \mathrm{kWh}[17,20,21]$. These variations are caused primarily by differing system boundaries, for instance the majority of the studies do not include the back-end of the fuel cycle. Notably, figures for decommissioning also vary quite considerably, from as low as 0.01 to as high as $35 \mathrm{~g} \mathrm{CO}_{2} / \mathrm{kWh}$ [17] - even higher than total emissions from the entire nuclear fuel cycle calculated by the majority of studies.

If it is assumed an average burnup of $40 \mathrm{GWd} / \mathrm{teU}$ for the nuclear fuel in the reactor and a conversion efficiency (thermal to electric) of one third, it is possible to estimate the consumption of uranium per $\mathrm{kWh}$ generated being equal to $3.13 \mathrm{E}-10 \mathrm{teU} / \mathrm{kWh}$. The global warming impact score for the management of 1 teU of UNFs assessed in this study is equal to $2.38 \mathrm{E}+05 \mathrm{~kg} \mathrm{CO}_{2} / \mathrm{teU}$, which equals $0.075 \mathrm{~g} \mathrm{CO}_{2}$ per $\mathrm{kWh}$ that has been generated by the fuel being managed (according to the figure for uranium consumption per $\mathrm{kWh}$ estimated above). Therefore, the carbon intensity of the back-end of the fuel cycle as considered in this study is almost negligible compared to that of the entire fuel cycle. Greenhouse gas emissions of nuclear energy are mainly caused by energy intensive phases like mining and milling, conversion and enrichment.

\section{Conclusions}

This study presented a comprehensive Life Cycle Assessment of used nuclear fuels management in the UK that envisaged their reprocessing and disposal of nuclear waste in a Geological Disposal Facility (GDF). The foreground system inventory is based on a combination of operational data for the Sellafield site and a preliminary design of a GDF considered for implementation in the UK [37]. The impact assessment phase is based on the ILCD recommendations, enhanced with two radiological impact categories for direct discharges and nuclear waste disposed in a GDF.

The normalisation of the LCA results indicated that the ionising radiations category has the highest score amongst the environmental categories considered. Although it is argued that this may be caused by an inconsistency between the geographical coverage of the product system and the reference system used for normalisation, the result can be explained by considering that few countries in Europe have nuclear power, and even fewer carry out reprocessing operations. The hot-spot analysis revealed that the majority of environmental impacts is due to use of uranyl nitrate for separating uranium from plutonium in the Thermal Oxide Reprocessing Plant (THORP), and of copper in the disposal canister assumed for disposal of High Level Waste (HLW). Efforts on improving the environmental performance of used nuclear fuels reprocessing should thus focus on reducing the use of copper and uranyl nitrate. Impacts associated with the GDF are generally minor (especially for categories with high normalised score) and mainly attributable to construction and decommissioning phases. Comparison with the results from other LCA studies shows that the carbon intensity of the back-end of the nuclear fuel cycle as calculated in this study is almost negligible with respect to the entire nuclear fuel cycle. As 
future work, the authors are looking into investigating several options for use and disposal of uranium and plutonium oxides in the UK.

\section{Acknowledgments}

The authors wish to thank the Nuclear Decommissioning Authority (NDA) for the financial support provided through the DISTINCTIVE (Decommissioning, Immobilisation and Storage soluTlons for NuClear wasTe InVEntories) programme [64].

\section{Glossary}

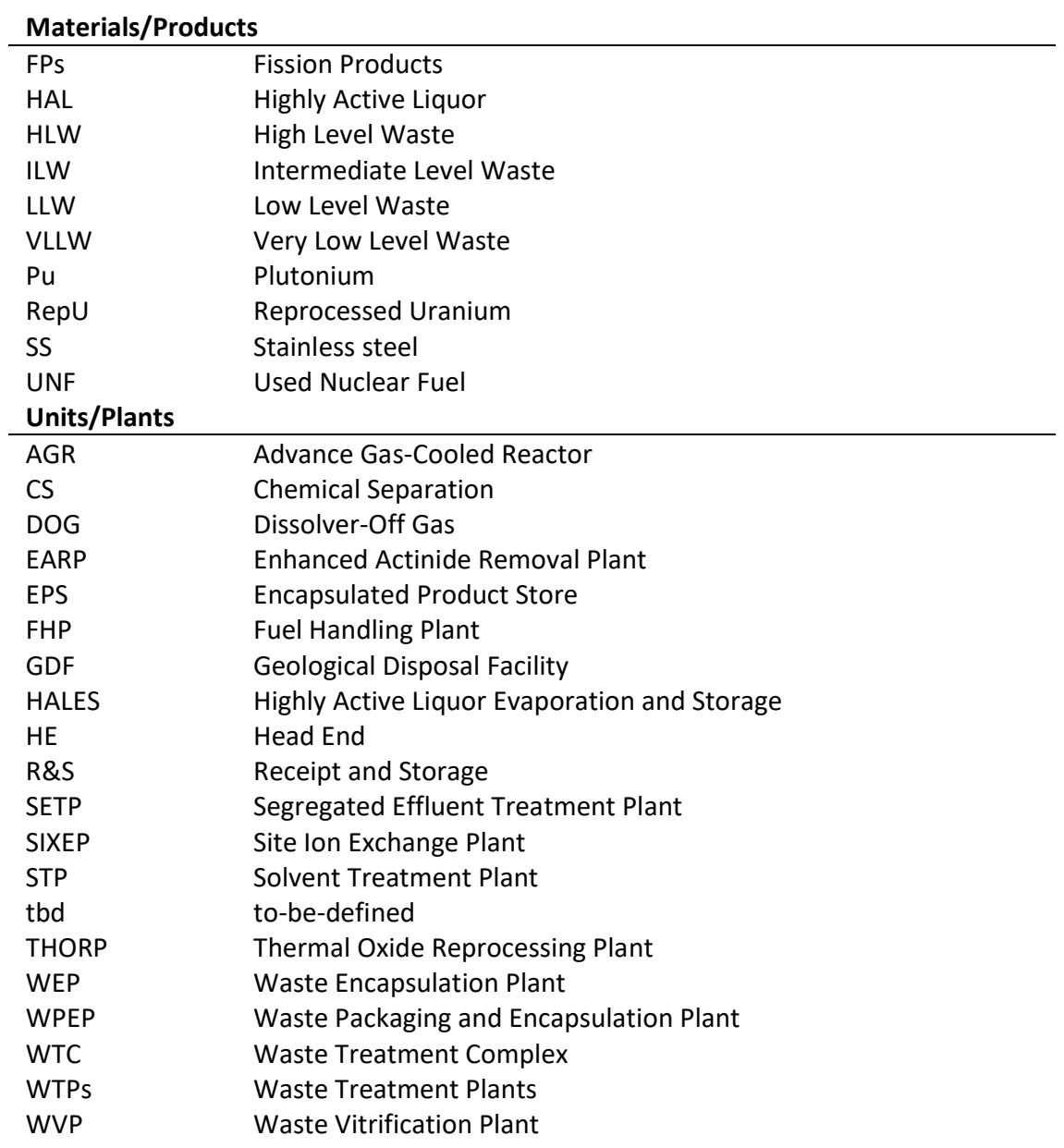

\section{References}

[1] WNA, Nuclear Development in the United Kingdom, (2016). https://www.worldnuclear.org/information-library/country-profiles/countries-t-z/appendices/nucleardevelopment-in-the-united-kingdom.aspx (accessed May 24, 2019).

[2] BEIS, Digest of United Kingdom Energy Statistics. Chapter 5, electricity., 2019. https://assets.publishing.service.gov.uk/government/uploads/system/uploads/attachment_d ata/file/840015/DUKES_2019_MASTER_COPY.pdf.

[3] WNA, Nuclear Power in the United Kingdom, (2020). http://www.worldnuclear.org/information-library/country-profiles/countries-t-z/united-kingdom.aspx (accessed May 20, 2020).

[4] WNA, China's Nuclear Fuel Cycle, (2019). http://www.world-nuclear.org/informationlibrary/country-profiles/countries-a-f/china-nuclear-fuel-cycle.aspx (accessed May 24, 2019). 
[5] WNA, Japan's Nuclear Fuel Cycle, (2019). http://www.world-nuclear.org/informationlibrary/country-profiles/countries-g-n/japan-nuclear-fuel-cycle.aspx (accessed May 25, 2019).

[6] IAEA, Country Nuclear Power Profiles - China, (2017). https://cnpp.iaea.org/countryprofiles/China/China.htm (accessed January 10, 2018).

[7] P.D. Wilson, The Nuclear Fuel Cycle: From Ore To Waste, Oxford University Press, New York, 1996.

[8] CoRWM, Managing our Radioactive Waste Safely: CoRWM's Recommendations to Government, (2006) 195.

[9] DECC, Implementing Geological Disposal, 2014.

[10] WNA, National Policies and Funding, (2017). http://www.world-nuclear.org/informationlibrary/nuclear-fuel-cycle/nuclear-wastes/appendices/radioactive-waste-managementappendix-3-national-p.aspx (accessed May 24, 2019).

[11] ISO, Environmental Management - Life Cycle Assessment - Principles and Framework. EN ISO 14040:2006, 2006.

[12] ISO, Environmental Management - Life Cycle Assessment - Requirements and guidelines. EN ISO 14044:2006, 2006. https://www.iso.org/obp/ui/\#iso:std:iso:14044:ed-1:v1:en.

[13] M.Z. Hauschild, R.K. Rosenbaum, S.I. Olsen, Life Cycle Assessment: Theory and Practice, Springer International Publishing, 2018. https://doi.org/10.1007/978-3-319-56475-3.

[14] R. Dones, T. Heck, M. Faist Emmenegger, N. Jungbluth, Life Cycle Inventories for the Nuclear and Natural Gas Energy Systems, and Examples of Uncertainty Analysis (14 pp), Int. J. Life Cycle Assess. 10 (2004) 10-23. https://doi.org/10.1065/lca2004.12.181.2.

[15] B. Solberg-Johansen, Environmental Life Cycle Assessment of the Nuclear Fuel Cycle. PhD thesis., University of Surrey, 1998.

[16] C. Poinssot, S. Bourg, N. Ouvrier, N. Combernoux, C. Rostaing, M. Vargas-Gonzalez, J. Bruno, Assessment of the environmental footprint of nuclear energy systems. Comparison between closed and open fuel cycles, Energy. 69 (2014) 199-211. https://doi.org/10.1016/j.energy.2014.02.069.

[17] M. Seier, T. Zimmermann, Environmental impacts of decommissioning nuclear power plants: methodical challenges, case study, and implications, Int. J. Life Cycle Assess. 19 (2014) 19191932. https://doi.org/10.1007/s11367-014-0794-2.

[18] S. Wallbridge, A. Banford, A. Azapagic, Life cycle environmental impacts of decommissioning Magnox nuclear power plants in the UK, Int. J. Life Cycle Assess. 18 (2013) 990-1008. https://doi.org/10.1007/s11367-012-0534-4.

[19] M. Lenzen, Life cycle energy and greenhouse gas emissions of nuclear energy: A review, Energy Convers. Manag. (2008). https://doi.org/10.1016/j.enconman.2008.01.033.

[20] J. Beerten, E. Laes, G. Meskens, W. D'haeseleer, Greenhouse gas emissions in the nuclear life cycle: A balanced appraisal, Energy Policy. 37 (2009) 5056-5068. https://doi.org/10.1016/j.enpol.2009.06.073.

[21] B.K. Sovacool, Valuing the greenhouse gas emissions from nuclear power: A critical survey, Energy Policy. 36 (2008) 2950-2963. https://doi.org/10.1016/j.enpol.2008.04.017.

[22] C. Poinssot, S. Bourg, B. Boullis, Improving the nuclear energy sustainability by decreasing its environmental footprint. Guidelines from life cycle assessment simulations, Prog. Nucl. Energy. 92 (2016) 234-241. https://doi.org/10.1016/j.pnucene.2015.10.012.

[23] A. Paulillo, R. Clift, J.M. Dodds, A. Milliken, S.J. Palethorpe, P. Lettieri, Radiological impacts in Life Cycle Assessment. Part I: General framework and two practical methodologies., Sci. Total Environ. 708 (2020). https://doi.org/10.1016/j.scitotenv.2019.135179.

[24] A. Paulillo, R. Clift, J.M. Dodds, A. Milliken, S.J. Palethorpe, P. Lettieri, Radiological Impacts in Life Cycle Assessment. Part II: Comparison of Methodologies., Sci. Total Environ. 708 (2020). https://doi.org/10.1016/j.scitotenv.2019.134712. 
[25] A. Paulillo, Operationalising the use of Life Cycle Assessment to nuclear waste management. PhD Thesis, University College London, 2018.

[26] A. Paulillo, R. Clift, J. Dodds, A. Milliken, S. Palethorpe, P. Lettieri, Data supporting UCrad and CGM, two novel methodologies for radiological impacts in Life Cycle Assessment, Data Br. 28 (2020). https://doi.org/10.1016/j.dib.2019.104857.

[27] A. Paulillo, R. Clift, J. Dodds, A. Milliken, S. Palethorpe, P. Lettieri, Radiological Impact Assessment for Life Cycle Assessment studies: A Review and Possible Ways Forward, Environ. Rev. 26 (2018) 239-254. https://doi.org/10.1139/er-2018-0004.

[28] M.A. Curran, M. Mann, G. Norris, The international workshop on electricity data for life cycle inventories, in: J. Clean. Prod., 2005: pp. 853-862. https://doi.org/10.1016/j.jclepro.2002.03.001.

[29] Defra, BERR, DOENI, WAG, Managing Radioactive Waste Safely: A Framework for Implementing Geological Disposal, 2008. https://www.gov.uk/government/uploads/system/uploads/attachment_data/file/68927/738 6.pdf.

[30] R. Clift, A. Doig, G. Finnveden, The Application of Life Cycle Assessment to Integrated Solid Waste Management. Part 1 - Methodology, Process Saf. Environ. Prot. 78 (2000) 279-287. https://doi.org/10.1205/095758200530790.

[31] K.L. Hildred, P.S. Townson, G. V. Hutson, R.A. Williams, Characterisation of particulates in the BNFL Enhanced Actinide Removal Plant, Powder Technol. (2000). https://doi.org/10.1016/S0032-5910(99)00216-8.

[32] M.T. Harrison, Vitrification of High Level Waste in the UK, Procedia Mater. Sci. 7 (2014) 10-15. https://doi.org/10.1016/j.mspro.2014.10.003.

[33] SKB, Programme for Research, Development and Demonstration of Methods for the Management and Disposal of Nuclear Waste, including Social Science Research, 2004.

[34] Pöyry Energy Ltd, Development of the Derived Inventory for ILW \& LLW Based on the 2007 UK Radioactive Waste Inventory, 2010.

[35] UK Nirex Ltd, Outline Design for a Reference Repository Concept for UK High Level Waste/Spent Fuel, 2005.

[36] NDA, Geological Disposal: Generic Transport Safety Case main report, NDA/RWMD/021, 2010. https://doi.org/NDA Report no. NDA/RWMD/021.

[37] NDA, Geological Disposal: Generic Disposal Facility Designs, 2010. http://www.nda.gov.uk/publication/geological-disposal-generic-disposal-facility-designsdecember-2010.

[38] Pöyry Energy Ltd, Development of the Derived Inventory of HLW and Spent Fuels Based on the 2007 UK Radioactive Waste Inventory, 2010.

[39] Pöyry Energy Ltd, Production of the Derived Inventory for Uranium and Plutonium, 2010.

[40] A.J. Francis, R. Cather, I.G. Crossland, Nirex Reference Vault Backfill: Report on Current Status in 1994., 1997.

[41] WNA, Processing of Used Nuclear Fuel, (2018). http://www.world-nuclear.org/informationlibrary/nuclear-fuel-cycle/fuel-recycling/processing-of-used-nuclear-fuel.aspx (accessed May 24, 2019).

[42] G. Wernet, C. Bauer, B. Steubing, J. Reinhard, E. Moreno-Ruiz, B. Weidema, The ecoinvent database version 3 (part I): overview and methodology, Int. J. Life Cycle Assess. 21 (2016) 12181230. https://doi.org/10.1007/s11367-016-1087-8.

[43] NDA, The 2016 UK Radioactive Waste Inventory, (2016). http://ukinventory.nda.gov.uk/ (accessed June 9, 2017).

[44] R. Dones, C. Bauer, G. Doka, ecoinvent report No. 6-VII - Kernenergie, 2009. 
[45] A.M. Tillman, Significance of decision-making for LCA methodology, Environ. Impact Assess. Rev. 20 (2000) 113-123. https://doi.org/10.1016/S0195-9255(99)00035-9.

[46] M.A. Curran, Co-product and input allocation approaches for creating life-cycle inventory data: a literature review, Int. J. Life Cycle Assess. 12 (2007) 65-78.

[47] T. Ekvall, G. Finnveden, Allocation in ISO 14041: a critical review, J. Clean. Prod. 9 (2001) 197208. https://doi.org/10.1016/S0959-6526(00)00052-4.

[48] R. Heijungs, J.B. Guinée, Allocation and "what-if" scenarios in life cycle assessment of waste management systems, Waste Manag. 27 (2007) 997-1005. https://doi.org/10.1016/j.wasman.2007.02.013.

[49] JRC, Recommendations for Life Cycle Impact Assessment in the European context - based on existing environmental impact assessment models and factors, 2011. https://doi.org/10.278/33030.

[50] JRC, Characterisation factors of the ILCD Recommended Life Cycle Impact Assessment methods: database and supporting information, European Commission Joint Research Centre, 2012. https://doi.org/10.2788/60825.

[51] L. Benini, L. Mancini, S. Sala, E. Schau, S. Manfredi, R. Pant, Normalisation method and data for Environmental Footprints, 2014. https://doi.org/10.2788/16415.

[52] S. Sala, L. Benini, L. Mancini, R. Pant, Integrated assessment of environmental impact of Europe in 2010 : data sources and extrapolation strategies for calculating normalisation factors, 2015. https://doi.org/10.1007/s11367-015-0958-8.

[53] Thinkstep, Gabi Product Sustainability Sofware, (2017). http://www.gabi-software.com/ukireland/index/ (accessed September 25, 2017).

[54] R. Heijungs, J. Guinée, R. Kleijn, V. Rovers, Bias in normalization: Causes, consequences, detection and remedies, Int. J. Life Cycle Assess. 12 (2007) 211-216. https://doi.org/10.1065/lca2006.07.260.

[55] WNA, World Uranium Mining Production, (2019). http://www.world-nuclear.org/informationlibrary/nuclear-fuel-cycle/mining-of-uranium/world-uranium-mining-production.aspx (accessed May 20, 2020).

[56] US-EPA, lodine-129 in the Environment Around a Nuclear Fuel Reprocessing Plant, Washington, 1972.

https://nepis.epa.gov/Exe/ZyNET.exe/9100OHSC.TXT?ZyActionD=ZyDocument\&Client=EPA\&I ndex $=$ Prior+to+1976\&Docs $=\& Q$ uery $=\&$ Time $=\&$ EndTime $=\&$ SearchMethod $=1 \&$ TocRestrict $=$ n \& Toc $=\&$ TocEntry $=\& Q F i e l d=\& Q F i e l d Y e a r=\& Q F i e l d M o n t h=\& Q F i e l d D a y=\& \operatorname{IntQFieldOp}=0 \&$ ExtQFi eldOp $=0 \&$ XmlQuery $=\&$.

[57] NDA, Geological Disposal: Generic post-closure safety assessment, 2010.

[58] I. Bakas, M.Z. Hauschild, T.F. Astrup, R.K. Rosenbaum, Preparing the ground for an operational handling of long-term emissions in LCA, Int. J. Life Cycle Assess. 20 (2015) 1444-1455. https://doi.org/10.1007/s11367-015-0941-4.

[59] H. Feiveson, Z. Mian, M. Ramana, F. Von Hippel, Managing spent fuel from nuclear power reactors: Experience and lessons from around the world, 2011.

[60] D.S. Hall, P.G. Keech, An overview of the Canadian corrosion program for the long-term management of nuclear waste, Corros. Eng. Sci. Technol. 52 (2017) 2-5. https://doi.org/10.1080/1478422X.2016.1275419.

[61] S. Watson, R. Metcalfe, International Precedents for HLW / SF Iron Canister Concepts Review and Consideration of Applicability in the UK. QRS-1376A-1., 2007.

[62] NFRC, Nuclear Fuel Cycle Royal Commission Report, 2016.

[63] WNA, Storage and Disposal of Radioactive Wastes, (2018). http://www.worldnuclear.org/information-library/nuclear-fuel-cycle/nuclear-wastes/storage-and-disposal-ofradioactive-wastes.aspx (accessed May 24, 2019). 
[64] DISTINCTIVE, (2017). http://distinctiveconsortium.org/. 


\section{Nuclear Fuel Cycles}

Once-Through Fuel Cycle

- Twice-Through Fuel Cycle

Uranium Mine

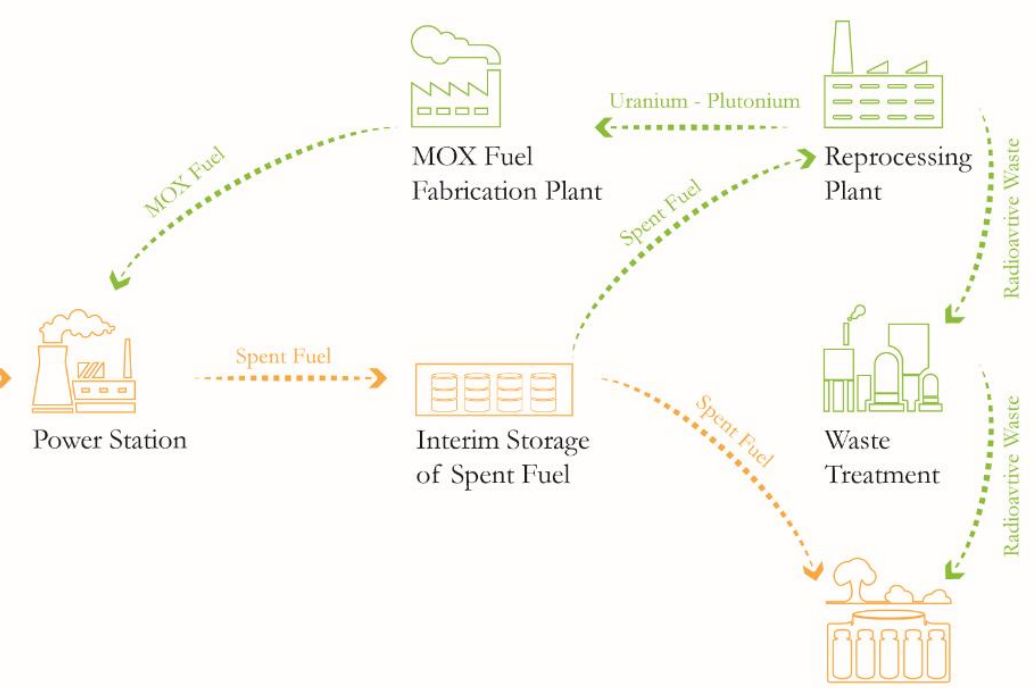

Geological Disposal Facility

Figure 1 - Schematic illustration of the Once-Through and Twice-Through fuel cycles.

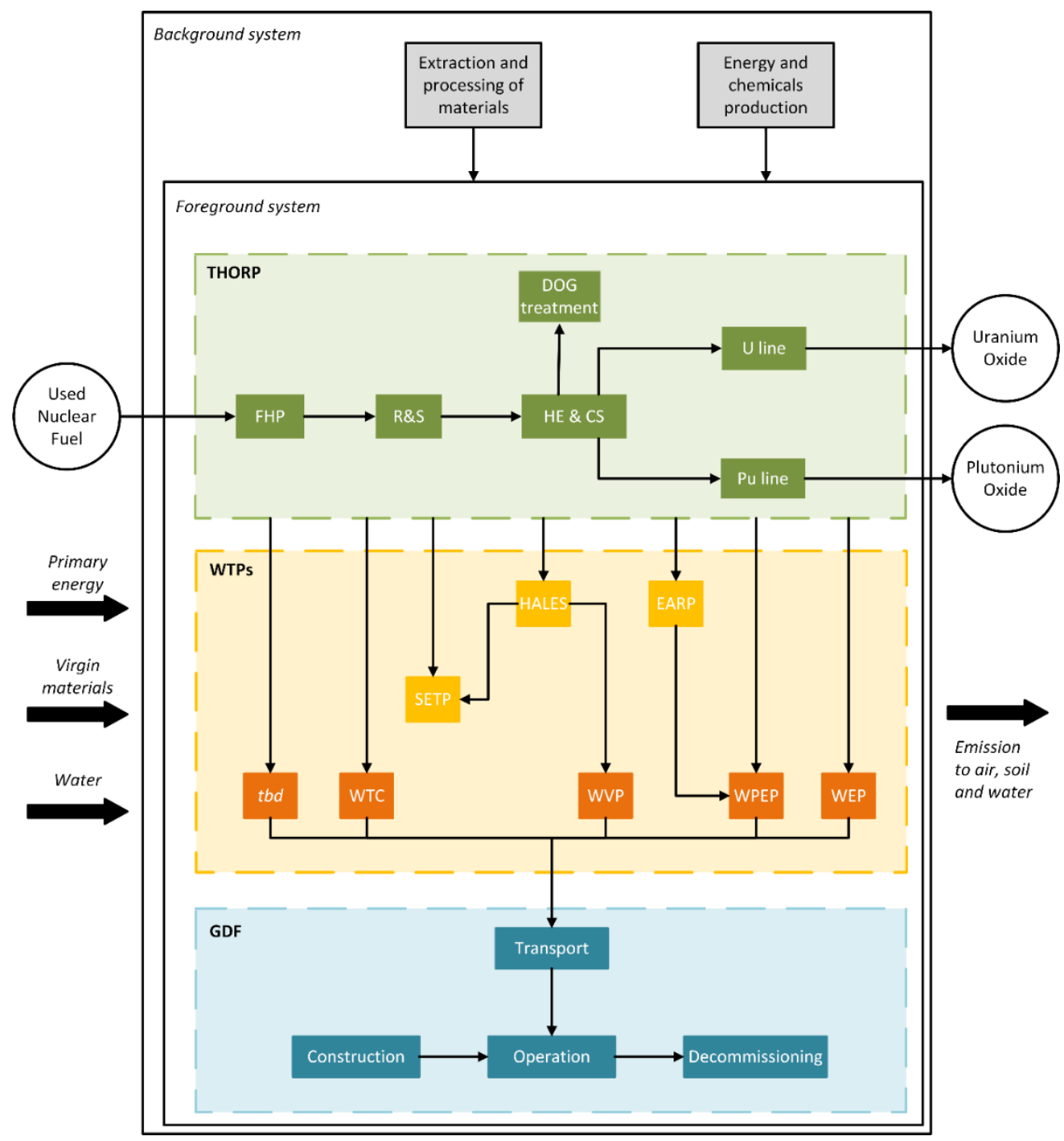

Figure 2 - System boundary of used nuclear fuels management. THORP: Thermal Oxide Reprocessing Plant; WTPs: Waste Treatment Plants; GDF: Geological Disposal Facility; FHP: Fuel Handling Plant; R\&S: Receipt and Storage; HE \& CS: Head End 
and Chemical Separation; DOG: Dissolver Off-Gas; tbd: to-be-defined (identifies a future plant); WTC: Waste Treatment Complex. SETP: Segregated Effluent Treatment Plant. HALES: Highly Active Liquor Evaporation and Storage; WVP: Waste Vitrification Plant. EARP: Enhanced Actinide Removal; WPEP: Waste Packaging and Encapsulation Plant; WEP: Waste Encapsulation Plant.

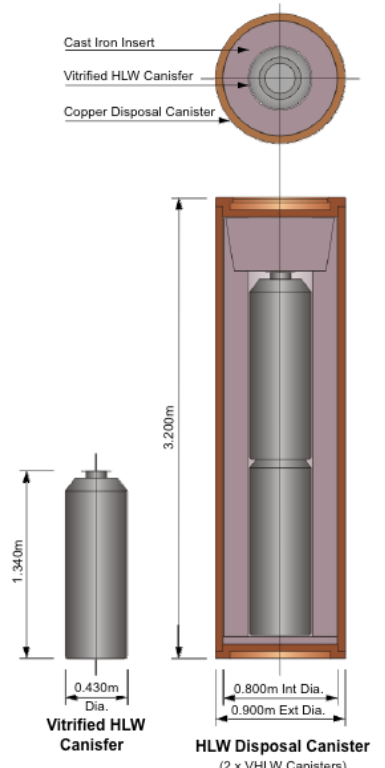

Figure 3 - The KBS-3V concept for disposal of HLW (adapted from [35])

Table 1 - Impact categories analysed

\begin{tabular}{|c|c|c|}
\hline Impact category & Metric & Acronym \\
\hline Acidification & [Mole of $\mathrm{H}^{+}$eq.] & A \\
\hline Climate change & {$\left[\mathrm{kg} \mathrm{CO}{ }_{2}\right.$ eq. $]$} & CC \\
\hline Ecotoxicity freshwater & [CTUe] & ECf \\
\hline Eutrophication freshwater & [kg P eq.] & Ef \\
\hline Eutrophication marine & [kg N eq.] & Em \\
\hline Eutrophication terrestrial & [Mole of $\mathrm{N}$ eq.] & Et \\
\hline Human toxicity, cancer effects & [CTUh] & HT-C \\
\hline Human toxicity, non-cancer effects & [CTUh] & HT-nc \\
\hline lonizing radiations & [Bq U235 air eq.] & IR \\
\hline lonizing radiations, waste & [Bq U238 ILW eq.] & IRw \\
\hline Ozone depletion & [kg CFC-11 eq.] & OD \\
\hline Particulate matter/respiratory inorganics & [kg PM2.5 eq.] & $\mathrm{PM} / \mathrm{RI}$ \\
\hline Photochemical ozone formation & [kg NMVOC] & POF \\
\hline Resource depletion, mineral, fossils and renewables & [kg Sb eq..] & $\mathrm{RDm}$ \\
\hline Resource depletion, water & [ $\mathrm{m}^{3}$ eq. $]$ & RDw \\
\hline
\end{tabular}

Table 2 - Normalisation factors for the lonising Radiation (IR) category

\begin{tabular}{lccc} 
Impact category & Unit & Domestic & Persons equivalent \\
\hline lonising radiations & $\mathrm{kBq} \mathrm{U235}$ air-eq./y & $1.08 \mathrm{E}+11$ & $2.16 \mathrm{E}+02$
\end{tabular}




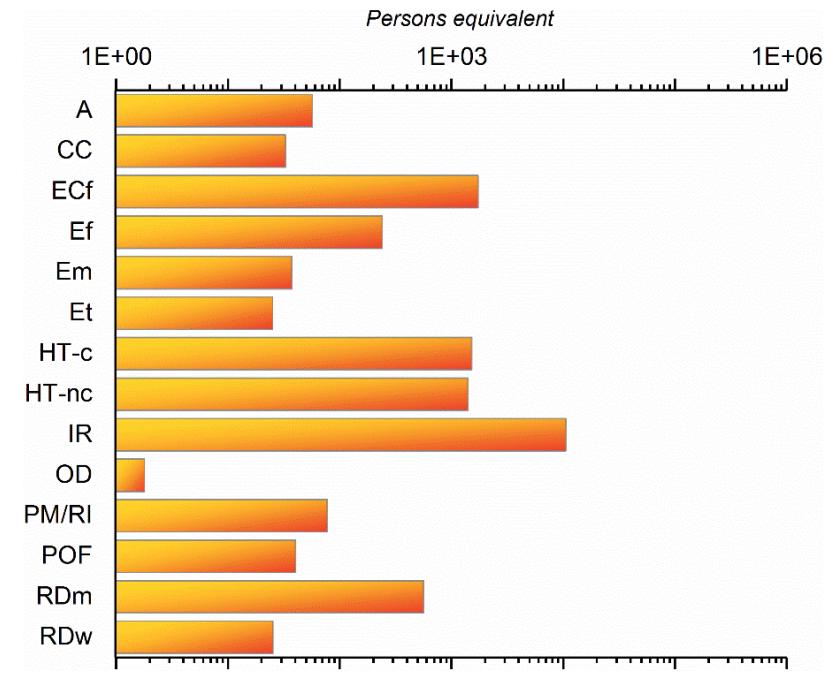

Figure 4 - Normalised impacts for the product system reported in Figure 2

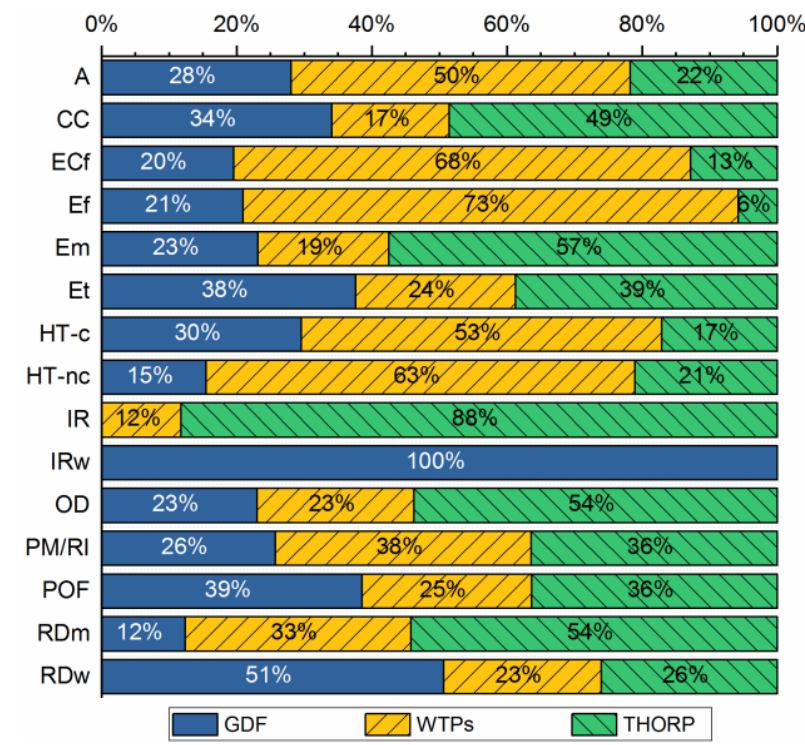

Figure 5 - Hot-spot analysis of the three main subsystems. GDF: Geological Disposal Facility; WTPs: Waste Treatment Plants; THORP: Thermal Oxide Reprocessing Plant. 


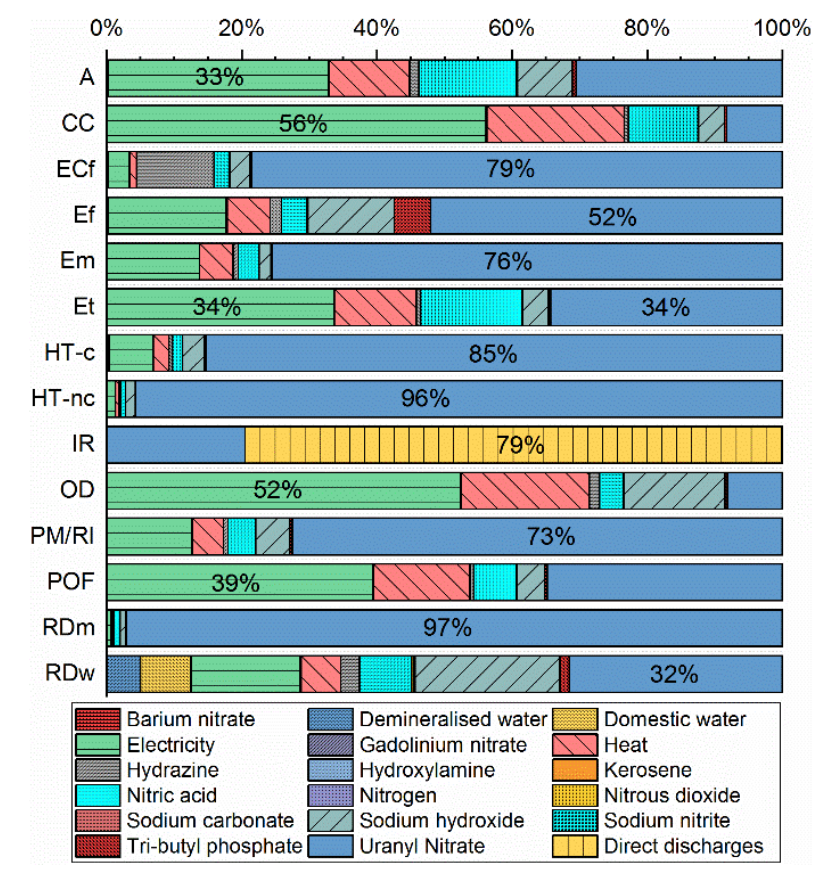

Figure 6 - Detailed hot-spot analysis for THORP subsystem, including indirect and direct burdens.

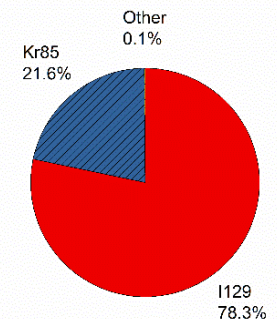

Figure 7 - Radionuclides breakdown for lonising Radiation impacts from THORP atmospheric discharges

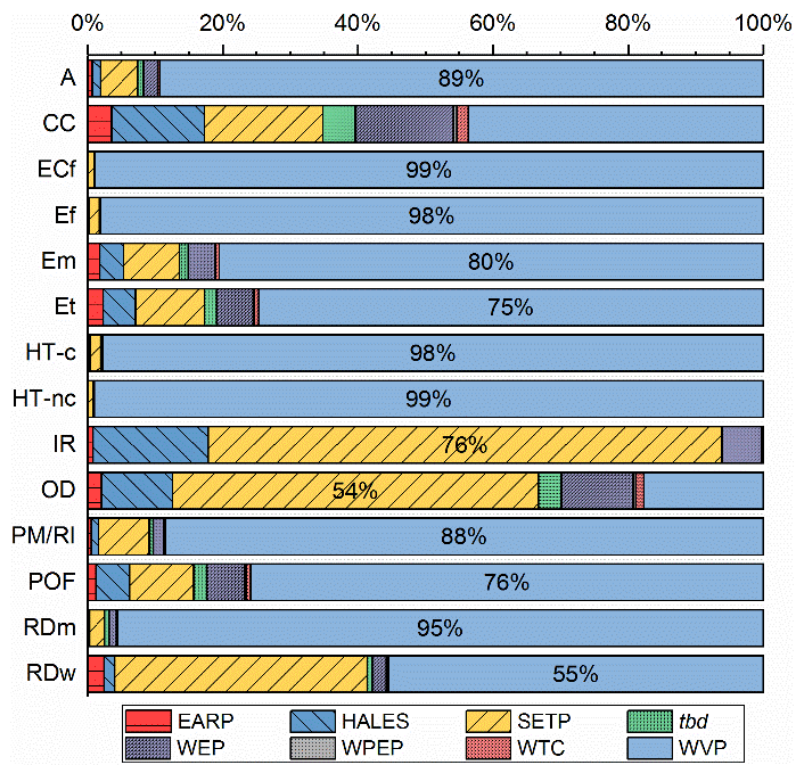

Figure 8 - Detailed hot-spot analysis of the Waste Treatment Plants subsystem. WTC: Waste Treatment Complex. SETP: Segregated Effluent Treatment Plant. HALES: Highly Active Liquor Evaporation and Storage; WVP: Waste Vitrification Plant. EARP: Enhanced Actinide Removal; WPEP: Waste Packaging and Encapsulation Plant; WEP: Waste Encapsulation Plant. 

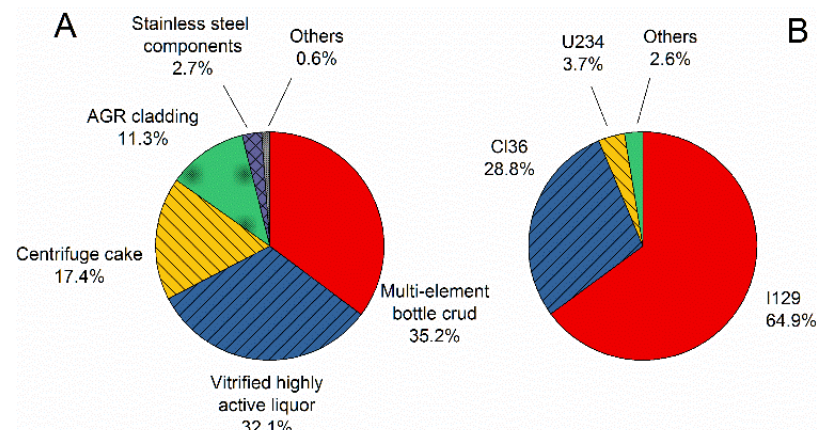

Figure 9-Detailed hot-spot analysis for lonising Radiation (waste) impact from GDF. A: Breakdown by solid waste streams; B: Breakdown by radionuclides.

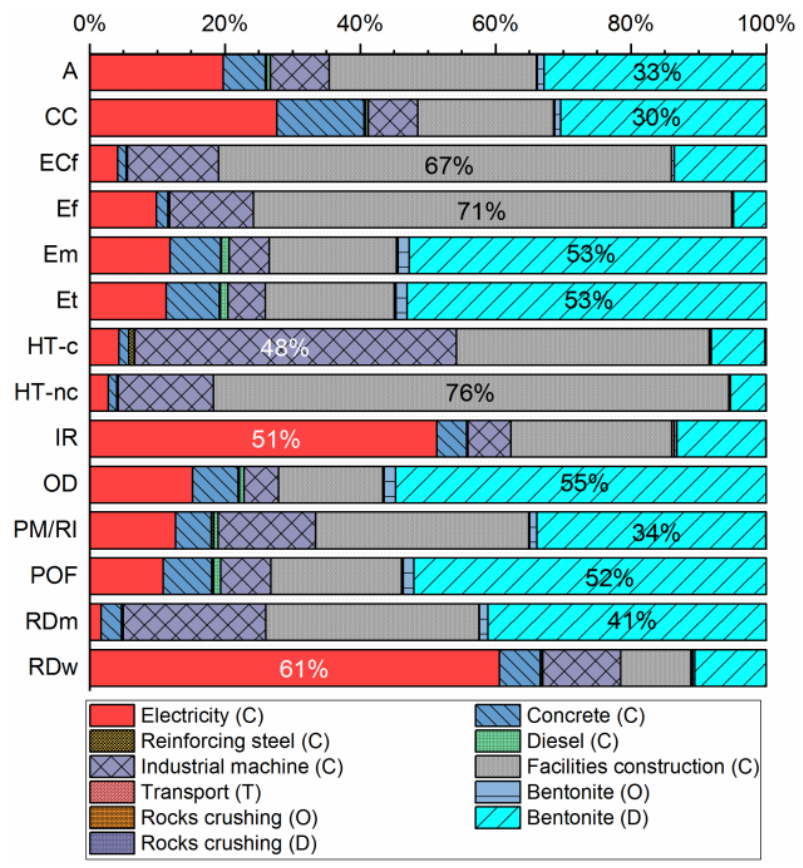

Figure 10 - Detailed hot-spot analysis for construction, transportation, operation and decommissioning of GDF for Vitrified HAL. C : Construction; O: Operation; T: Transportation; D: Decommissioning. 